\title{
A reversible contraceptive action of some 6-chloro-6-deoxy sugars in the male rat
}

\author{
W. C. L. Ford and G. M. H. Waites \\ Department of Physiology \& Biochemistry, The University, Whiteknights, Reading RG6 2AJ, U.K.
}

\begin{abstract}
Summary. Male rats given daily doses of $240 \mu \mathrm{mol}$ 6,6'-dichloro-6,6'-dideoxysucrose or 6'-chloro-6'-deoxysucrose or 6-chloro-6-deoxysucrose/ $\mathrm{kg}$ for 28 days became infertile after 7 days and remained infertile during treatment. Fertility was partly recovered 3 weeks after the last dose and completely restored by 6 weeks. 6-Chloro-6deoxyglucose and 6-chloro-6-deoxyfructose were also effective at this dose, but $6,1^{\prime}, 6^{\prime}$ trichloro-6,1',6'-trideoxysucrose, 4,1',6'-trichloro-4,1',6'-trideoxygalactosucrose, 4,6,$4^{\prime}, 6^{\prime}$-tetrachloro-4,6,4',6'-tetradeoxygalactotrehalose and methyl-6-chloro-6-deoxy- $\alpha$ D-glucopyranoside were not.
\end{abstract}

Spermatozoa from the cauda epididymidis of infertile rats oxidized glucose more slowly than did spermatozoa from controls.

\section{Introduction}

The antifertility action of low doses of $\alpha$-chlorohydrin (3-chloropropan-1,2-diol) on the male (Ericsson \& Youngdale, 1970) is associated with a marked reduction in the ability of spermatozoa from treated animals to oxidize glucose (Mohri, Suter, Brown-Woodman, White \& Ridley, 1975; Edwards, Dacheux \& Waites, 1976; Ford, Harrison \& Waites, 1977) and it is possible that this may be the primary cause of the antifertility action. With the glycolytic effect in mind, we have examined the action of some chlorinated sugars on the fertility of male rats.

\section{Materials and Methods}

\section{Fertility tests}

Experiment 1 . The sugars tested were 6,6'-dichloro-6,6'-dideoxysucrose (Text fig. 1), 6-chloro-6deoxysucrose and 6'-chloro-6'-deoxysucrose (Khan, Jenner \& Mufti, 1975; Khan, 1976); these and all other chlorodeoxysugars were synthesized by Dr H. F. Jones, Dr R. Khan and Dr M. R. Jenner at the Philip Lyle Memorial Research Laboratory, Tate and Lyle Ltd, Reading, U.K. Gas-liquid chromatography of trimethyl-silyl ethers showed that 6-chloro-6-deoxysucrose contained about $10 \%$ of an unknown impurity, whilst the other compounds appeared pure ( $\mathrm{H}$. Lindseth, personal communication).

The sugars were administered by oral gavage as aqueous solutions to male $C D$ rats (Charles River UK Ltd, Manston, Kent) weighing 350-420 g. The 7 rats in each group received daily doses of $1 \mathrm{ml}$ water $/ \mathrm{kg}$ (Group I, controls), 120 (Group II) or 240 (Group III) $\mu \mathrm{mol}$ 6,6'-dichloro-6,6'-dideoxysucrose $/ \mathrm{kg}$ (45 or $90 \mathrm{mg} / \mathrm{kg}$ ), $240 \mu \mathrm{mol}$ 6-chloro-6-deoxysucrose $/ \mathrm{kg}$ ( $85 \mathrm{mg} / \mathrm{kg}$ : Group IV) or 240 $\mu \mathrm{mol} 6$ 6'-chloro-6'-deoxysucrose $/ \mathrm{kg}$ ( $85 \mathrm{mg} / \mathrm{kg}$ : Group V). A fresh virgin female (CD strain, 250$300 \mathrm{~g}$ body weight; Charles River UK Ltd) was paired with each of the males for 7 days after he had been dosed for 7, 14 and 21 days. After 28 days dosing was stopped and 3 males from each group were killed. Further females were introduced to the other 4 males for 7 days, 3 and 6 weeks after the 28-day treatment period. Vaginal smears were taken to confirm normal oestrous cycles before pairing and to check insemination. The females introduced after dosing for 21 days were killed 18 days after mating or allowed to litter; the other females were killed 10-13 days after mating and embryos and corpora lutea were counted. Subsequent trials were carried out in a similar manner with the modifications described below. 


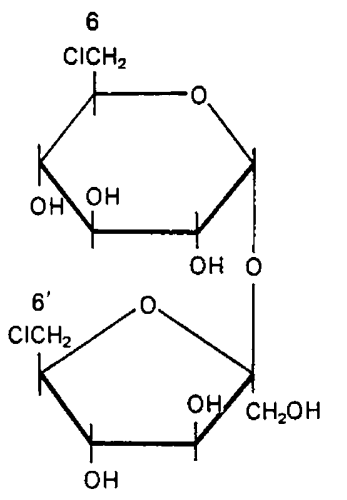

Text-fig. 1. The structure of 6,6'-dichloro-6,6'-dideoxysucrose.

Experiment 2. Five groups of 5 male CD rats were given daily doses of $120 \mu \mathrm{mol}$ sucrose/kg (Group A, controls), 60 (Group B) or 120 (Group C) $\mu \mathrm{mol} 6^{\prime}$-chloro-6'-deoxysucrose/kg (21 or 43 $\mathrm{mg} / \mathrm{kg}$ ), $240 \mu \mathrm{mol}$ 6-chloro-6-deoxyglucose $/ \mathrm{kg}$ (48 mg/kg: Group D) (Evans \& Parrish, 1972) or 240 $\mu \mathrm{mol}$ 6-chloro-6-deoxyfructose $/ \mathrm{kg}$ (48 mg/kg: Group E) for 14 days. 6-Chloro-6-deoxyfructose was prepared by acid hydrolysis of $6^{\prime}$-chloro-6'-deoxysucrose and was not separated from the equimolar glucose produced in the reaction. After treatment for 7 days each male was paired with a female for 7 days. Females were killed 10 days after mating as in Exp. 1. Males in Groups D and E were placed with another female 3 weeks after the 14-day dosing period.

\section{Sperm metabolism}

These experiments were performed on those rats from Exp. 1 killed after 28 days. Blood was collected from the heart immediately after death and glucose was measured by the hexokinase procedure (Bergemeyer, 1974). Spermatozoa were expelled from the cauda epididymidis by retrograde flushing (Ford et al., 1977) and pooled within each group. They were dispersed in phosphatebuffered saline (100 mM-NaCl, $3 \mathrm{mM}-\mathrm{KCl}, 6.5 \mathrm{~mm}-\mathrm{Na}_{2} \mathrm{HPO}_{3}, 1.5 \mathrm{~mm}-\mathrm{KH}_{2} \mathrm{PO}_{4}, 0.8 \mathrm{~mm}-\mathrm{CaCl}_{2}$ and $0.5 \mathrm{~mm}-\mathrm{MgCl}_{2}$ ) (PBS) (Edwards et al., 1976) containing $90 \mu \mathrm{g}$ penicillin $\mathrm{G}$ and $120 \mu \mathrm{g}$ streptomycin sulphate $/ \mathrm{ml}$. Duplicate aliquots $\left(3 \mathrm{ml} ; 0.74-0.84 \times 10^{8}\right.$ spermatozoa) were incubated with $6 \mu \mathrm{mol}$ $(3 \mu \mathrm{Ci}) \mathrm{D}-\left[\mathrm{U}-{ }^{14} \mathrm{C}\right]$ glucose (Radiochemical Centre, Amersham) for $2 \mathrm{~h}$ at $34^{\circ} \mathrm{C}$ in stoppered $10 \mathrm{ml}$ conical flasks in a shaking water bath. The reaction was terminated by the addition of $1.5 \mathrm{ml} 1.5$ M-perchloric acid. The ${ }^{14} \mathrm{CO}_{2}$ liberated was trapped in $1 \mathrm{ml}$ hyamine hydroxide $(0.2 \mathrm{M}$ solution in toluene) dispersed on glass wool and the radioactivity was estimated following the addition of $5 \mathrm{ml}$ scintillant. Denatured spermatozoa were removed from the reaction medium by centrifugation and the supernatant was neutralized to $\mathrm{pH} 6$ by addition of $2 \cdot 3 \mathrm{M}-\mathrm{K}_{2} \mathrm{CO}_{3}$ containing $0.7 \mathrm{M}-2-(\mathrm{N}-$ morpholino)ethanesulphonic acid. ATP was assayed fluorometrically (Williamson \& Corkey, 1969).

The motility of the cells was assessed by visual estimation $(\times 100$ magnification, dark-field illumination) of the proportion of cells with active flagella, both before the incubation and after standing for $2 \mathrm{~h}$ in the experimental medium.

\section{Results}

\section{Fertility tests}

Experiment 1. The rats in Groups III, IV and V were infertile after 1 week and the effect was sustained after 2 and 3 weeks (Table 1): the effect of $6^{\prime}$-chloro-6'-deoxysucrose was complete. In Group II the antifertility effect was incomplete. In all groups fertility was partly recovered by 3 weeks after the last dose and completely restored by 6 weeks (Table 1 ). Throughout the experiment the body weight and behaviour of the male rats were normal and there was no effect on blood glucose con $-30 \mathrm{AM}$ 
Table 1. The effect of three chlorinated sucroses on the fertility of male rats treated daily for 28 days and tested individually with different females at various times after the start of dosing: the first 3 males in each group were killed on Day 28 (see Table 2)

\begin{tabular}{|c|c|c|c|c|c|c|c|c|c|c|}
\hline \multirow{4}{*}{$\frac{\text { Group }}{\frac{\text { I (control, } 1 \mathrm{ml}}{\text { water } / \mathrm{kg} / \text { day })}}$} & \multirow{3}{*}{$\begin{array}{c}\text { Weeks } \\
\text { since } \\
\text { first } \\
\text { dose }\end{array}$} & \multicolumn{8}{|c|}{ No. of implantations } & \multirow{3}{*}{$\begin{array}{c}\begin{array}{c}\text { Average } \\
\text { con- } \\
\text { ception } \\
\text { rate }(\%)^{*}\end{array} \\
86\end{array}$} \\
\hline & & \multicolumn{7}{|c|}{$\begin{array}{l}\text { Live (and resorbing) in } \\
\text { individual females }\end{array}$} & \multirow{2}{*}{$\begin{array}{c}\text { Mean } \\
17 \cdot 3\end{array}$} & \\
\hline & & 19 & 19 & 16 & 17 & 18 & 15 & 17 & & \\
\hline & 2 & 16 & 17 & 14 & 13 & $14(1)$ & 12 & $16(3)$ & $15 \cdot 2$ & 89 \\
\hline & 3 & 13 & 17 & 14 & 16 & 16 & 0 & 0 & 10.9 & 69 \\
\hline & 7 & - & - & - & 15 & 16 & 13 & 11 & 13.8 & 91 \\
\hline & 10 & - & - & - & 12 & 15 & 15 & 18 & 15 & 97 \\
\hline \multirow{5}{*}{$\begin{array}{l}\text { II (120 } \mu \mathrm{mol} \\
6,6^{\prime} \text {-dichloro-6,6'- } \\
\text { dichlorosucrose/ } \\
\mathrm{kg} / \text { day) }\end{array}$} & 1 & 0 & 5 & 16 & 0 & $12(1)$ & 3 & 0 & $5 \cdot 2$ & 27 \\
\hline & 2 & 9 & 1 & $15(1)$ & 0 & 0 & 12 & 0 & $5 \cdot 4$ & 32 \\
\hline & $3 \dagger$ & 14 & 3 & 0 & 0 & - & 17 & 16 & $8 \cdot 3$ & - \\
\hline & 7 & - & - & - & 16 & 0 & 15 & 7 & $9 \cdot 5$ & 56 \\
\hline & 10 & - & - & - & 14 & 15 & 12 & 15 & 14 & 93 \\
\hline \multirow{5}{*}{$\begin{array}{l}\text { III }(240 \mu \mathrm{mol} \\
6,6^{\prime} \text {-dichloro-6,6'- } \\
\text { dichlorosucrose/ } \\
\mathrm{kg} / \text { day })\end{array}$} & 1 & 2 & 0 & 0 & 0 & 0 & 0 & 0 & 0.3 & 0.3 \\
\hline & 2 & 0 & 0 & 0 & 0 & 0 & 0 & 0 & 0 & 0 \\
\hline & 3 & 0 & 1 & 0 & 0 & 0 & 0 & 5 & 0.9 & $4 \cdot 7$ \\
\hline & 7 & - & - & - & 0 & 16 & 14 & 19 & $12 \cdot 3$ & 70 \\
\hline & 10 & - & - & - & 15 & 15 & 13 & 12 & $13 \cdot 8$ & 95 \\
\hline \multirow{5}{*}{$\begin{array}{l}\text { IV }(240 \mu \mathrm{mol} \\
\text { 6-chloro-6-deoxy- } \\
\text { sucrose/kg/day) }\end{array}$} & 1 & 0 & 0 & 1 & 0 & 0 & 0 & 0 & $0 \cdot 1$ & $0 \cdot 1$ \\
\hline & 2 & 0 & 1 & 0 & 0 & 0 & 0 & 0 & 0.1 & 0.1 \\
\hline & 3 & $\mathbf{0}$ & 0 & 0 & $\mathbf{0}$ & $\mathbf{0}$ & $\mathbf{0}$ & $\mathbf{0}$ & 0 & 0 \\
\hline & 7 & - & - & - & 14 & 13 & 11 & 12 & $12 \cdot 5$ & 89 \\
\hline & 10 & - & - & - & 15 & $-\pi$ & 12 & 12 & 13 & 98 \\
\hline \multirow{5}{*}{$\begin{array}{l}\mathrm{V}(240 \mu \mathrm{mol} \\
6^{\prime} \text {-chloro-6'-deoxy- } \\
\text { sucrose } / \mathrm{kg} / \text { day })\end{array}$} & 1 & 0 & 0 & 0 & 0 & $-\S$ & 0 & 0 & 0 & 0 \\
\hline & 2 & 0 & 0 & 0 & 0 & - & 0 & 0 & 0 & 0 \\
\hline & 3 & o & 0 & 0 & 0 & - & 0 & 0 & 0 & 0 \\
\hline & 7 & - & - & - & 6 & - & 7 & 15 & $9 \cdot 3$ & 63 \\
\hline & 10 & - & - & - & 17 & - & 8 & 13 & $12 \cdot 6$ & 81 \\
\hline
\end{tabular}

centrations measured in the males killed after 28 days. The ability to mate was confirmed by detection of spermatozoa in vaginal smears and the morphology of all fetuses, including litters of reduced size sired by males of Group II, was normal.

No abnormalities could be detected with the naked eye in the 3 rats of each group killed $20 \mathrm{~h}$ after the last dose and the weights of the testes and accessory organs were similar in control and treated rats. Examination of spermatozoa expelled from the cauda epididymidis showed that their concentration, morphology and motility were similar in all groups. Spermatozoa from the rat cauda epididymidis do not exhibit strong progressive motility but $50-75 \%$ of the cells had active flagella at zero time and 10-20\% after standing for $2 \mathrm{~h}$.

Experiment 2. The average conception rates were: Group A (controls), 79\%; Group B, 81\%; Group C, 12\%; Group D, 0\% and Group E, 0\%. Therefore 6'-chloro-6'-deoxysucrose was without effect at a dose of $60 \mu \mathrm{mol} / \mathrm{kg} /$ day but was partly effective when $120 \mu \mathrm{mol} / \mathrm{kg} /$ day were given. These data suggest that the antifertility activity may be slightly greater than that of $6,6^{\prime}$-dichloro-6,6'dideoxysucrose. 6-Chloro-6-deoxyglucose and 6-chloro-6-deoxyfructose rendered the males infertile, but by 3 weeks after cessation of treatment the conception rates had recovered to 86 and $92 \%$ respectively.

$6,1^{\prime}, 6^{\prime}$ - Trichloro - $6,1^{\prime}, 6^{\prime}$ - trideoxysucrose, $4,1^{\prime}, 6^{\prime}$ - trichloro $-4,1^{\prime}, 6^{\prime}$ - trideoxygalactosucrose,

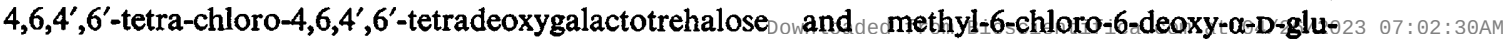


Table 2. The oxidation of $\mathrm{D}-\left[\mathrm{U}-{ }^{14} \mathrm{C}\right]$ glucose by spermatozoa flushed from each cauda epididymidis of rats treated daily with chlorinated sucroses and the ATP content of the cells after the incubation

\begin{tabular}{clcc}
\hline Group & \multicolumn{1}{c}{ Treatment } & $\begin{array}{c}\text { nmol glucose converted } \\
\text { to } \mathrm{CO}_{2} / 10^{8} \text { sperm. } \\
(\% \text { of control })\end{array}$ & $\begin{array}{c}\text { nmol ATP } / 10^{8} \text { sperm. } \\
\text { (\% of control) }\end{array}$ \\
\hline I & Control $(1 \mathrm{ml}$ water $/ \mathrm{kg} /$ day) & $52(100)$ & $18 \cdot 5(100)$ \\
& $6,6^{\prime}$-Dichloro-6,6'-dideoxysucrose & $14 \cdot 9(28 \cdot 7)$ & $2 \cdot 8(14 \cdot 9)$ \\
II & $120 \mu \mathrm{mol} / \mathrm{kg} /$ day & $2 \cdot 8(5 \cdot 3)$ & $1 \cdot 9(10 \cdot 3)$ \\
III & $240 \mu \mathrm{mol} / \mathrm{kg} /$ day & $1 \cdot 4(2 \cdot 6)$ & $5 \cdot 0(26 \cdot 8)$ \\
IV & $6-$ Chloro-6-deoxysucrose, $240 \mu \mathrm{mol} / \mathrm{kg} /$ day & $2 \cdot 7(5 \cdot 2)$ & $2 \cdot 5(13 \cdot 4)$ \\
V & $6^{\prime}$-Chloro-6'-deoxysucrose, $240 \mu \mathrm{mol} / \mathrm{kg} /$ day & & \\
\hline
\end{tabular}

The values are the means of duplicate determinations on spermatozoa pooled from 3 rats in each group.

copyranoside) were also tested in doses of up to $240 \mu \mathrm{mol} / \mathrm{kg} / \mathrm{day}$ for 2 weeks in similar experiments but the fertility of male rats was not affected.

\section{Sperm metabolism}

The metabolism of glucose to carbon dioxide was dramatically inhibited in spermatozoa from rats in Groups III, IV and V and partly inhibited in those from rats in Group II (Table 2). Spermatozoa from treated rats had a lower ATP content than those from controls after incubation for $2 \mathrm{~h}$, suggesting an imbalance in energy metabolism caused by reduced glucose oxidation.

\section{Discussion}

It is possible that the chlorodeoxysucroses are hydrolysed during their uptake from the gut (Crane, 1969) because 6-chloro-6-deoxyglucose and 6-chloro-6-deoxyfructose also exhibited antifertility activity. If this were so, 6,6'-dichloro-6,6'-dideoxysucrose should be twice as effective as either monochlorodeoxysucrose, but it is possible that it is less easily hydrolysed owing to the presence of an extra chlorine atom. The introduction of further chlorine atoms reduced rather than enhanced the antifertility effect and blocking the $1^{\prime}$ position of sucrose with chlorine or the 1 position of glucose by methylation abolished activity. Our results are consistent with a mechanism of action whereby the chlorodeoxysugars, or a product derived from them, can reduce the ability of epididymal spermatozoa to metabolize carbohydrate and so prevent the spermatozoa from generating sufficient energy to meet their requirements in the period between ejaculation and fertilization.

We have been unable to demonstrate any effect on glycolysis by incubating spermatozoa from untreated rats with 6-chloro-6-deoxyglucose at concentrations up to $50 \mathrm{~mm}$. This suggests that the sugars are metabolized to an active product before exerting their antifertility effect. However, the nature of this metabolism is difficult to predict since most common pathways of sugar metabolism commence with phosphorylation of the 6 position of the hexose molecule which is blocked by chlorine in these compounds. Another explanation would be that the observed lesion in sperm glycolysis is a consequence of a primary lesion in the epididymis.

The activity of these compounds is reminiscent of that of $\alpha$-chlorohydrin but there is reason to believe that they may be much less toxic because a group of 20 mice given a single oral dose of $16 \mathrm{~g}$ 6,6'-dichloro-6,6'-dideoxysucrose $/ \mathrm{kg}$ and a group of 20 rats given 6-chloro-6-deoxyglucose at the same dose did not exhibit any toxic effects (H. F. Jones, personal communication). Chlorodeoxysugars therefore represent a new family of compounds worthy of further investigation with a view to their development as male contraceptive agents in man.

We thank Dr H. F. Jones and Dr R. Khan of Tate and Lyle Ltd for stimulating discussions; Ms Anne Harrison for assistance with the biochemical measurements; and Mr J. F. Gaitens, Mr J. Millard and Mr R. J. Parrott for help with the fertility trials. The material in this publication is the subject of a patent application by Tate and Lyle Ltd (Folio No. 1069477), and the investigation was supported by Grant No. 73511 of the WorldHealth Organization.ifica.com at 04/26/2023 07:02:30AM 


\section{References}

BeRGEMEYeR, H.U. (1974) D-glucose. Determination with hexokinase and glucose-6-phosphate dehydrogenase, In Methods of Enzymatic Analysis (2nd English edition), Vol. III, pp. 1196-1200. Ed. H. U. Bergemeyer. Academic Press, New York.

CRANE, R.K. (1969) Functional organization contributing to carbohydrate economy. In Comprehensive Biochemistry, Vol. 17, pp. 1-15. Eds M. Florkin \& E. H. Stotz. Elsevier, Amsterdam.

Edwards, E.M., DacheuX, J.-L. \& Waites, G.M.H. (1976) Effects of $\alpha$-chlorohydrin on the metabolism of testicular and epididymal spermatozoa of rams. J. Reprod. Fert. 48, 265-270.

Ericsson, R.J. \& Youngdale, G.A. (1970) Male antifertility compounds; structure and activity relationships of U-5897, U-15,646 and related substances. $J$. Reprod. Fert. 21, 263-266.

Evans, M.E. \& PARRISH, F.W. (1972) 6-Chloro-6deoxy- $\alpha$-D-glucose. From methyl- $\alpha$-D-glucopyranoside by reaction with methanesulphonyl chloride in $\mathrm{N}, \mathrm{N}$-dimethylformamide. In Methods in Carbohydrate Chemistry, Vol. VI, pp. 193-196. Eds R. L.
Whistler \& J. N. B. Miller. Academic Press, New York.

FoRd, W.C.L., HaRRISON, A. \& WaITES, G.M.H. (1977) Effects of the optical isomers of $\alpha$-chlorohydrin on glycolysis by ram testicular spermatozoa and the fertility of male rats. J. Reprod. Fert. 51, 105109.

KHAN, R. (1976) The chemistry of sucrose. Adv. Carbohydrate Chem. Biochem. 33, 235-294.

KHAN, R., JENNER, M.R. \& MUFI, K.S. (1975) Reaction of methane sulphonyl chloride. N,N-dimethylformamide with partially esterified derivatives of sucrose. Carbohydrate Res. 39, 253-262.

MOHRI, H., SUTER, D.A.I., BROWN-WOOdMAN, P.D.C., WhITE, I.G. \& RIDLEY, D.D. (1975) Identification of the biochemical lesion produced by $\alpha$-chlorohydrin in spermatozoa. Nature, Lond. 255, 75-77.

Williamson, J.R. \& CORKEY, B.E. (1969) Assays of intermediates of the citric acid cycle and related compounds by fluorimetric enzyme methods. In Methods in Enzymology, Vol. 13, pp. 434-513. Ed. J.M. Lowenstein. Academic Press, New York.

Received 4 July 1977 